\author{
EVS27 \\ Barcelona, Spain, November 17-20, 2013
}

\title{
Component Design of $x$-EVs using Virtual Integrated Development Environment
}

\author{
Chao Ma ${ }^{1}$, Heejin Shin ${ }^{1}$, Seulgi Lee ${ }^{1}$, Minseok Song ${ }^{1}$, Jinhyun Park ${ }^{1}$, Choongmin Jeong ${ }^{1}$, \\ Sungho Hwang ${ }^{1}$, Myungwon Suh ${ }^{1}$, Kiyun Jeong ${ }^{2}$ and Hyunsoo Kim ${ }^{1}$ \\ ${ }^{I}$ School of Mechanical Engineering, Sungkyunkwan University, Suwon-Si, Korea, hskim@me.skku.ac.kr \\ ${ }^{2}$ Intelligent Vehicle Technology R\&D Division, Korea Automotive Technology Institute, Chonan, Korea
}

\begin{abstract}
In this study, component design of $\mathrm{x}$-EVs was performed using virtual integrated development environment (VIDE). First, component library was developed for various components such as the engine, motor, battery and transmission. Vehicle performance simulator of x-EVs was developed using MATALB SimDriveline, which consists of the powertrain system and control system. Experiment and commercial software were used for the validation. A virtual environment was developed using the 3D rendering tool to simulate the road, buildings, traffic, signal system and weather. Using the VIDE, EV range and acceleration performance for various $\mathrm{x}$-EVs were evaluated to design the battery and motor specifications. In addition, an electric heater was selected as an example and its performance at the vehicle level was investigated using the VIDE. It is expected that the VIDE can be used in component design for $\mathrm{x}$-EVs.
\end{abstract}

Keywords: $x-E V$, component design, virtual integrated development environment (VIDE)

\section{Introduction}

Due to the high oil price and $\mathrm{CO} 2$ emission, the development of environment friendly x-electric vehicles $(\mathrm{x}-\mathrm{EV}$ s) such as hybrid electric vehicle (HEV), plug-in HEV (PHEV) and electric vehicle (EV), have attracted the attention of the automobile manufacturers [1].

The $\mathrm{x}-\mathrm{EV}$ is constructed by several components such as transmission, engine, battery and motorgenerator(MG). Using the powertrain components, HEV and PHEV can be constructed with various configurations such as series, parallel and power-split, which have different power characteristics and control algorithms. Since the vehicle performance is directly related with the component design specifications, it is necessary to evaluate the component performance at the vehicle level as well as the component level. However, it is not easy to evaluate the vehicle level performance without applying the component to the target vehicle. Some researches had been performed on the component design and vehicle performance evaluation using the commercial softwares such as the powertrain system analysis tool (PSAT) developed by the Argonne National Laboratory and the Cruise developed by the AVL[2,3].

In this study, component design of $\mathrm{x}$-EVs was performed using the virtual integrated development environment (VIDE). $x-E V$ simulators were developed and validated. Battery and motor specifications were designed using VIDE. In addition, an electric heater was selected as a design example and its performance was investigated at the vehicle level using the VIDE. 


\section{Performance Simulator of $\mathrm{x}$ - EV}

In this study, EV (Nissan Leaf) and PHEV (Plugin Prius, GM-Volt) are selected as the $\mathrm{x}-\mathrm{EV}$ target vehicles.

The structures of the target vehicles are shown in Fig. 1. The target vehicle consists of engine, MGs, battery and transmission. The component specifications of the target $\mathrm{x}-\mathrm{EV}$ s are shown in Table 1 [4].

Table1: Component specifications

(a) Nissan Leaf

\begin{tabular}{|c|c|c|}
\hline \multirow{2}{*}{ MG2 } & Max output(kW) & 80 \\
\cline { 2 - 3 } & Max torque $(\mathrm{Nm})$ & 280 \\
\hline \multirow{2}{*}{ Battery } & Type & Lithium-ion \\
\cline { 2 - 3 } & Capacity $(\mathrm{kWh})$ & 24 \\
\hline
\end{tabular}

(b) Plug-in Prius

\begin{tabular}{|c|c|c|}
\hline \multirow{2}{*}{ Engine } & Displacement (cc) & 1798 \\
\cline { 2 - 3 } & Max output $(\mathrm{kW} / \mathrm{rpm})$ & $73 / 5,200$ \\
\hline \multirow{2}{*}{ MG2 } & Max output(kW) & 60 \\
\cline { 2 - 3 } & Max torque $(\mathrm{Nm})$ & 207 \\
\hline \multirow{2}{*}{ MG1 } & Max output $(\mathrm{kW})$ & $40^{*}$ \\
\hline \multirow{2}{*}{ Battery } & Type & Lithium-ion \\
\cline { 2 - 3 } & Capacity & $4.4 \mathrm{kWh}$ \\
\hline
\end{tabular}

(c) GM-Volt

\begin{tabular}{|c|c|c|}
\hline \multirow{2}{*}{ Engine } & Displacement (cc) & 1398 \\
\cline { 2 - 3 } & Max output $(\mathrm{kW} / \mathrm{rpm})$ & $64 / 4800$ \\
\hline \multirow{2}{*}{ MG2 } & Max output $(\mathrm{kW})$ & 111 \\
\cline { 2 - 3 } & Max torque $(\mathrm{Nm})$ & 370 \\
\hline \multirow{2}{*}{ MG1 } & Max output $(\mathrm{kW})$ & 55 \\
\hline \multirow{2}{*}{ Battery } & Type & Lithium-ion \\
\cline { 2 - 3 } & Capacity $(\mathrm{kWh})$ & 16 \\
\hline
\end{tabular}

\subsection{Component library}

Component library is developed for various components such as the engine, motor, battery and transmission system with various capacity and specification using MATLAB SimDriveline (Fig. 2).

In addition, the component library is designed to allow the user to change the size and characteristics, which provides the freedom in the evaluation of the component performance such as torque, speed, voltage, current and battery state of charge (SOC).

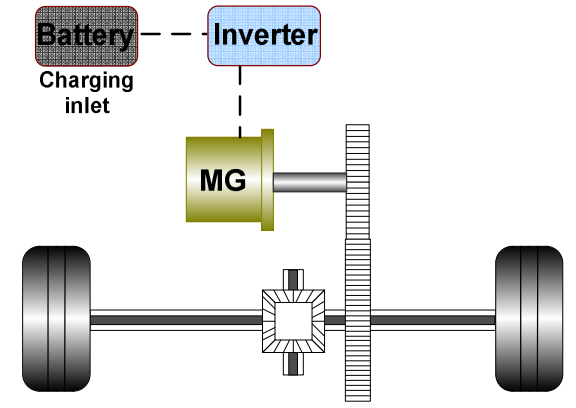

(a) Nissan Leaf

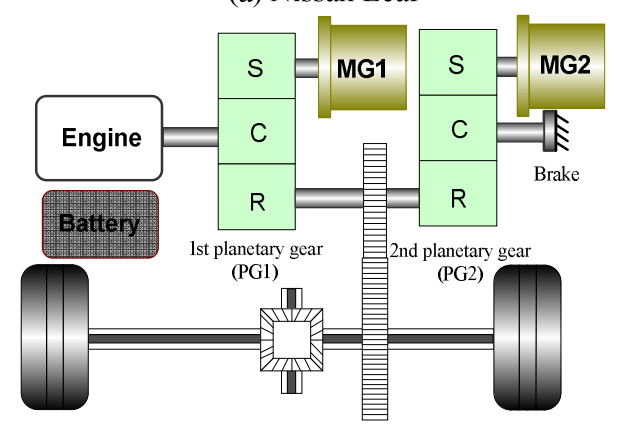

(b) Plug-in Prius

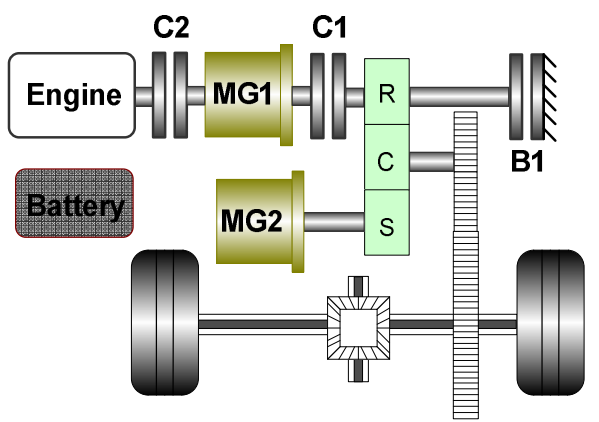

(c) GM-Volt

Figure1: Structure of $\mathrm{x}-\mathrm{EV}$ s (Nissan Leaf, Plug-in Prius, GM-Volt)

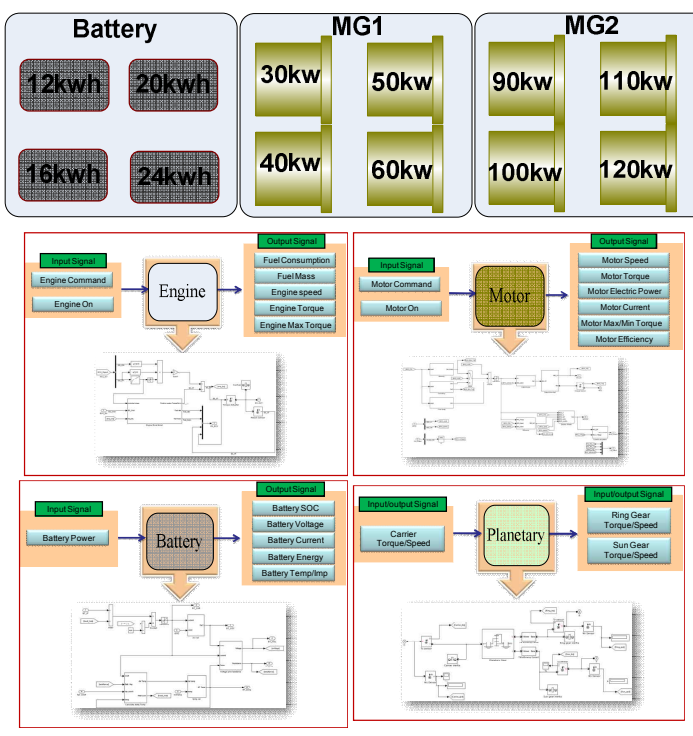

Figure2: Component library 


\subsection{Control system}

For the PHEV, the component control algorithm is developed for the engine, MG1 and MG2 considering the driving mode of the target vehicle (Fig. 3).

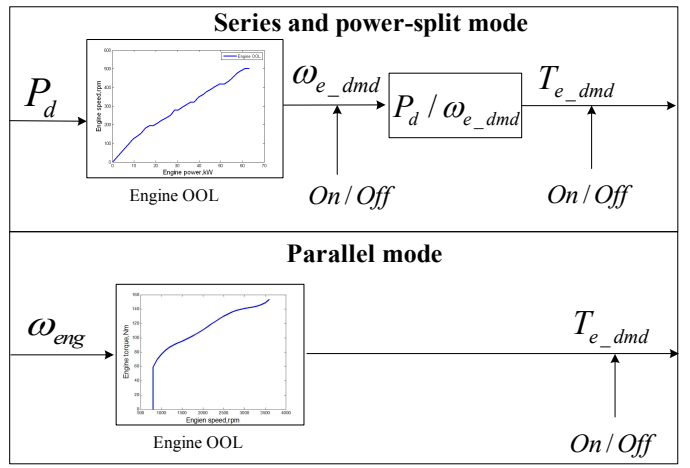

(a) Engine control algorithm

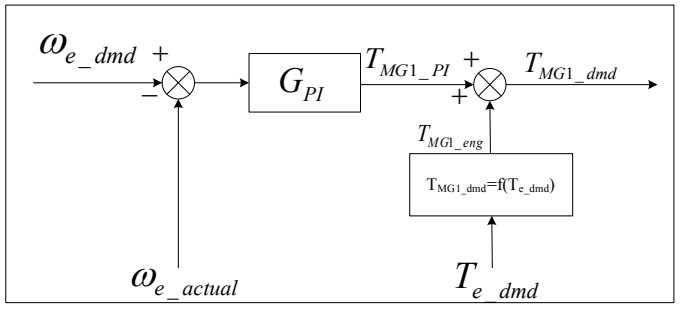

(b) MG1 control algorithm

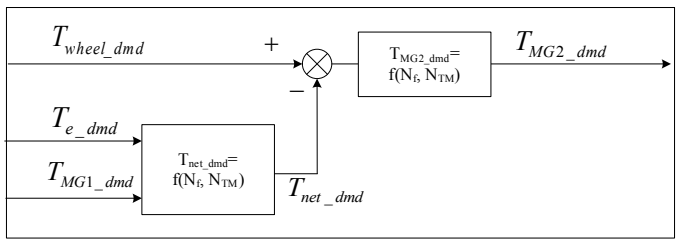

(c) MG2 control algorithm

Figure3: Component control algorithm

For the engine, control algorithm is developed for the optimal operation based on the engine optimal operating line (OOL). Since the engine optimal operation is realized by the MG1 control, a PI-type MG1 torque control is used for the engine speed control. The MG2 torque and the net torque that comes from the engine and MG1 are used together to propel the vehicle. The demanded MG2 torque is obtained by subtracting the net torque from the demanded wheel torque. In addition, an energy management strategy is developed for the PHEV considering the battery SOC (Fig. 4) [4]. The vehicle is driven under charge depleting (CD) mode when the battery is fully charged by the external electric grid. When the battery SOC drops to a predefined value, the drive mode of the PHEV is switched from the $\mathrm{CD}$ mode to the charge sustaining (CS) mode. The battery SOC is sustained in the CS mode [4].

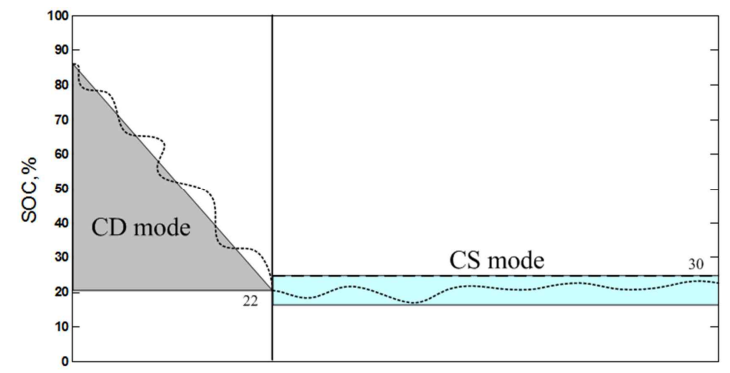

Figure4: Energy management strategy [4]

For the EV, only the component control algorithm is required and the demanded MG2 torque is obtained from the demanded wheel torque.

The performance simulator of the x-EVs was developed by combining the powertrain system and control system.

\section{Validation of $x-E V$ Performance Simulator}

The $\mathrm{x}$-EV performance simulators are validated by comparing with the commercial softwares and test results. The validation of the GM-Volt is performed in the previous research [5].

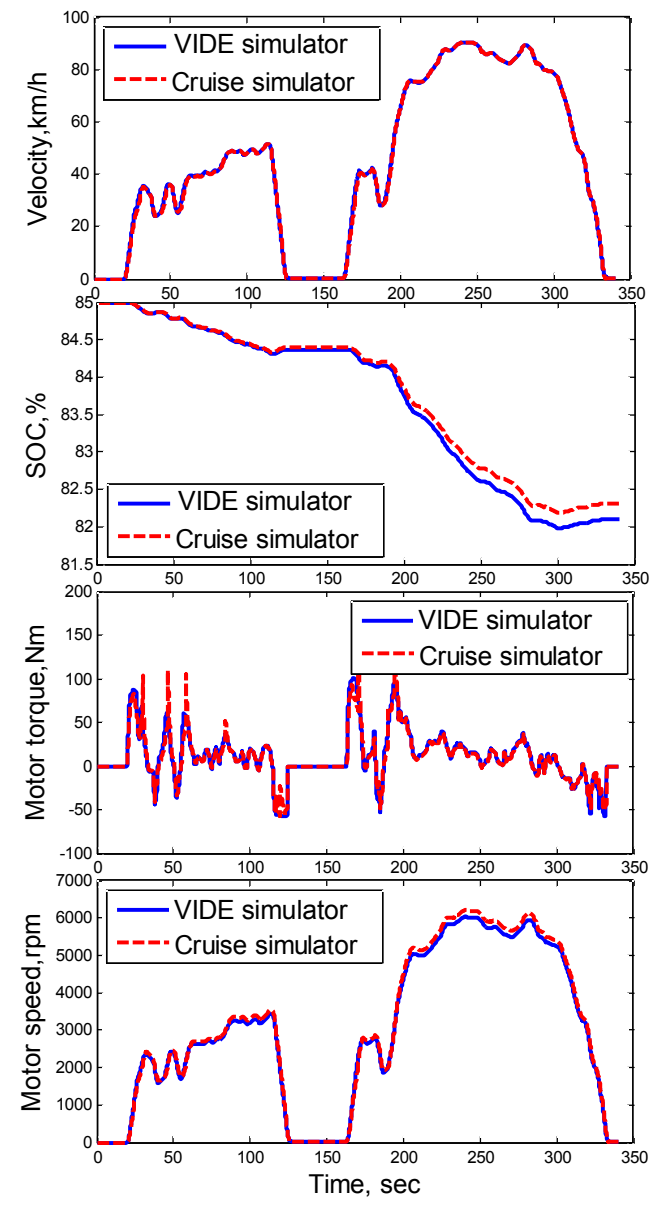

Figure5: Validation of Nissan Leaf using Cruise 

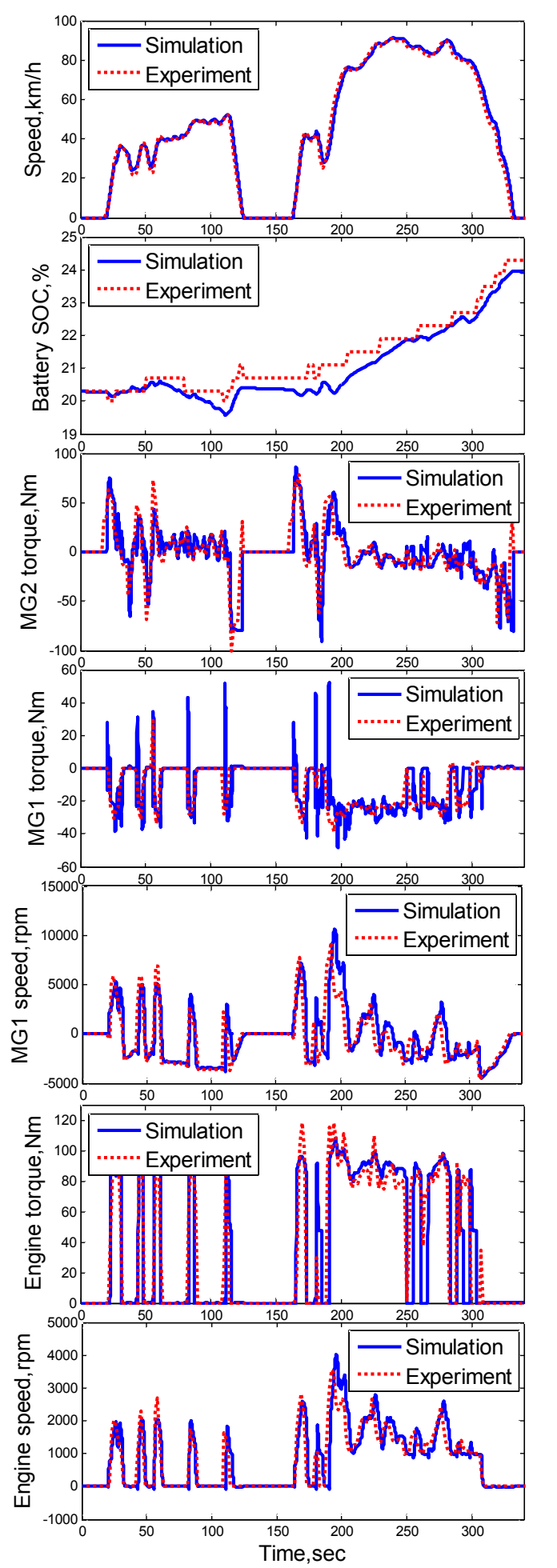

Figure6: Validation of plug-in Prius using test results

For the Nissan Leaf, commercial software Cruise is used for the validation (Fig. 5). It is seen that the VIDE simulation results of the vehicle velocity, battery SOC, motor speed and torque are in good accordance with the results of Cruise simulator.
Validation of the plug-in Prius is performed using test results (Fig. 6). From the comparison results, it is seen that the simulation results of the vehicle velocity, battery SOC, engine/MG1/MG2 torque and speed are in good accordance with the test results, which demonstrates the validity of the $\mathrm{x}$ EV performance simulator.

\section{Virtual Integrated Development Environment}

Based on the developed $x-E V$ performance simulator, a GUI environment is developed to select the vehicle platform and simulation type (Fig. 7). As shown in Fig. 7, the user can select the vehicle type, vehicle platform, simulation condition and send the selected vehicle to the virtual driving environment.

To perform the virtual driving, the virtual environment is developed using the $3 \mathrm{D}$ rendering tool, which can simulate the road, buildings, traffic, signal system and weather [6].

The real time driving devices are used to combine the $x-E V$ simulator and virtual driving environment (Fig. 8) [6]. The driver can manipulate the steering and accelerator/brake pedal to drive the vehicle in the virtual environment for various test conditions: simulation mode, test mode and virtual driving mode. At the same time, the component performance such as torque, speed, voltage, current and fuel economy are evaluated on real time feature (Fig. 9). For the virtual driving environment, a results management GUI is also developed [6].

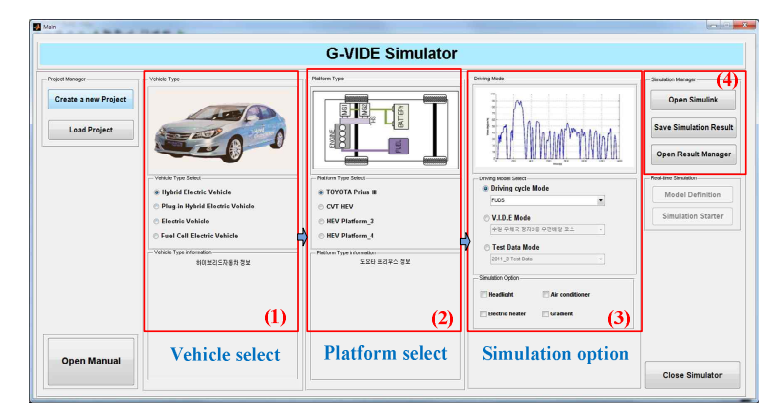

Figure7: GUI environment of VIDE [4] 


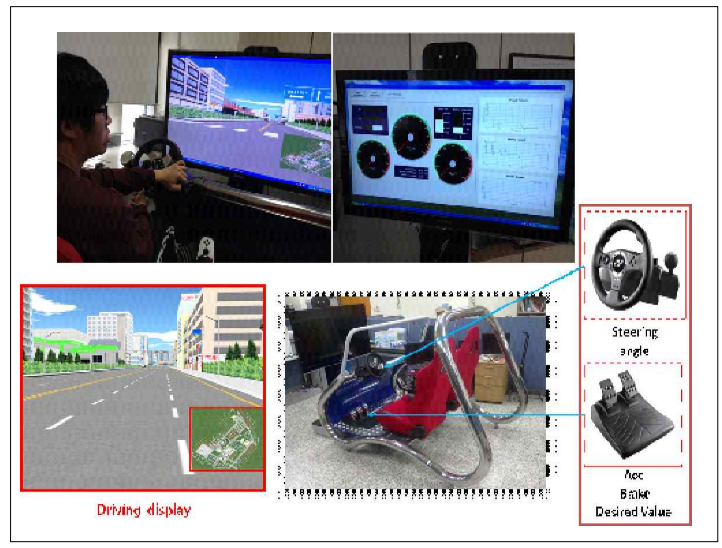

Figure8: Virtual integrated development environment

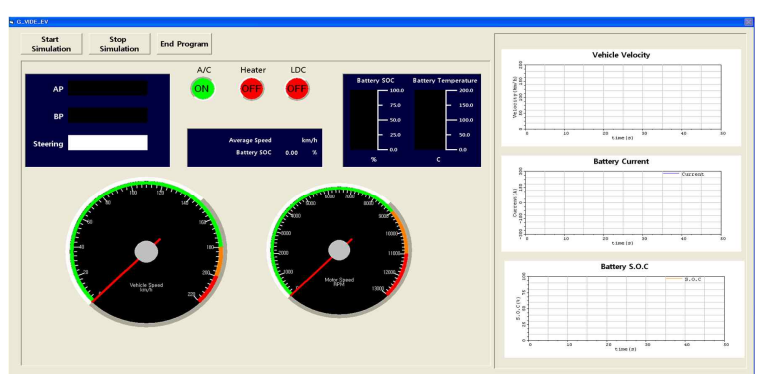

Figure9: Real time monitoring display

\section{Component Design using VIDE}

Using the VIDE, the EV range and acceleration performance are evaluated to determine the component design parameters.

\subsection{Battery}

For the PHEV and EV, the battery specifications such as the battery capacity have direct influence on the all electric driving range.

Using the VIDE, the EV range of the selected battery specifications for the target $\mathrm{x}$-EVs are obtained and compared with the official values (Table 2). From Table 2, it is seen that the simulation EV range of the target $\mathrm{x}$-EVs are similar with that of the official value. Using similar procedure, the battery capacity of the $\mathrm{x}-$ EVs can be designed by evaluating the EV range using the VIDE.

Table2: EV range for $\mathrm{x}-\mathrm{EV}$ s

\begin{tabular}{|c|c|c|c|}
\hline & Leaf & Prius & Volt \\
\hline Battery apacity $(\mathrm{kWh})$ & 24 & 4.4 & 16 \\
\hline$\triangle$ SOC & $70 \%$ & $60 \%$ & $63.8 \%$ \\
\hline VIDE EV range $(\mathrm{km})$ & 118.1 & 18.2 & 57.5 \\
\hline Official EV range $(\mathrm{km})$ & 117 & 18 & 56.3 \\
\hline
\end{tabular}

\subsection{Motor}

In the EV mode, the MG works as the power source to propel the vehicle and its design specifications has direct relationship with the vehicle acceleration performance.

Acceleration performance for the target $\mathrm{x}$-EVs is obtained using VIDE (Table 3). It is seen that the acceleration performance obtained from the VIDE has similar results with the official values.

Table3: Acceleration performance for x-EVs

\begin{tabular}{|c|c|c|c|}
\hline & Leaf & Prius & Volt \\
\hline Battery capacity $(\mathrm{kWh})$ & 24 & 4.4 & 16 \\
\hline Motor power $(\mathrm{kW})$ & 80 & $60 / 40$ & $111 / 55$ \\
\hline Vehicle mass $(\mathrm{kg})$ & 1520 & 1420 & 1815 \\
\hline VIDE $(0 \sim 100 \mathrm{kph}, \mathrm{sec})$ & 9.7 & 10.3 & 8.7 \\
\hline Official $(0 \sim 100 \mathrm{kph}, \mathrm{sec})$ & 9.9 & 10.7 & 9 \\
\hline
\end{tabular}

\subsection{Component design using VIDE}

For the PHEV and EV, an electric heater is required to warm the cabin in the winter since the battery is used as the energy source.

When the component manufacturer wants to design the electric heater, the influence of the electric heater on the vehicle performance such as the EV range should be investigated. The heater with the maximum power of $6 \mathrm{~kW}$ is selected for the performance investigation (Table 4).

Table4: Specifications of heater

\begin{tabular}{|c|c|}
\hline Nominal voltage $(\mathrm{V})$ & $300 \mathrm{~V}$ \\
\hline Heater power $(\mathrm{kW})$ & 6 \\
\hline Resistance number & 10 \\
\hline
\end{tabular}

The heater model is constructed, which consists of the heater resistance, core fin and air flow model (Fig. 10).

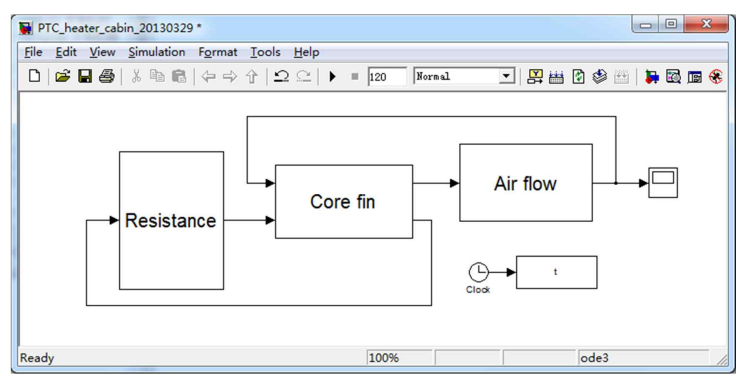

Figure10: Heater model 
The heat transfer process can be described as: heater resistance $\rightarrow$ core fin $\rightarrow$ air flow $\rightarrow$ cabin. The heat generated from the heater resistance is transferred to the core fin and the heat from the core fin is transferred to the cabin by the fan.

Cabin heat transfer model is developed (Fig. 11).

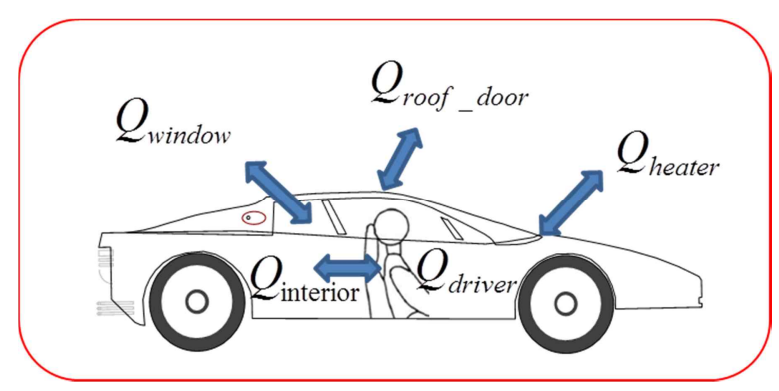

Figure 11: Cabin heat transfer model

The temperature in the cabin is obtained as

$T_{\text {cabin }}=\int \frac{P_{\text {air }}+P_{\text {driver }}-P_{\text {loss }}}{\rho V_{\text {cabin }} C_{p}} d t$

where $\mathrm{T}_{\text {cabin }}$ is temperature in cabin, $\mathrm{P}_{\text {air }}$ is the input air heat power, $\mathrm{V}_{\text {cabin }}$ is the cabin volume, $\mathrm{C}_{\mathrm{p}}$ is specific heat of air and $\mathrm{P}_{\text {loss }}$ is the power loss from window, roof, door etc.

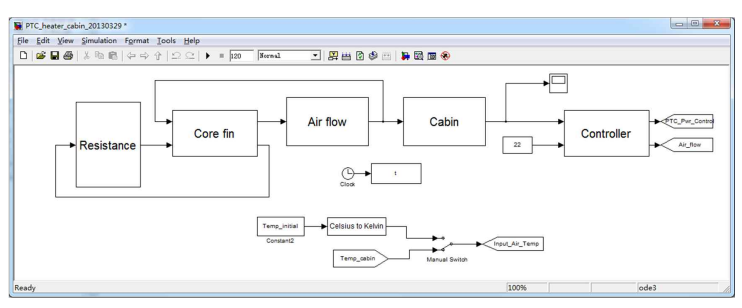

Figure12: Vehicle climate model

The vehicle climate model is constructed by combining the heater model and cabin heat transfer model (Fig. 12). Using the VIDE, the influence of the electric heater on the vehicle performance is investigated by applying the heater on the target vehicle (e.g., GM-Volt). The simulation conditions are shown in Table 5.

Table5: Simulation conditions

\begin{tabular}{|c|c|}
\hline Required temperature $\left({ }^{\circ} \mathrm{C}\right)$ & 10 \\
\hline External temperature $\left({ }^{\circ} \mathrm{C}\right)$ & -10 \\
\hline Occupants number & 2 \\
\hline Battery SOC $(\%)$ & $85.8 \% \sim 22 \%$ \\
\hline
\end{tabular}

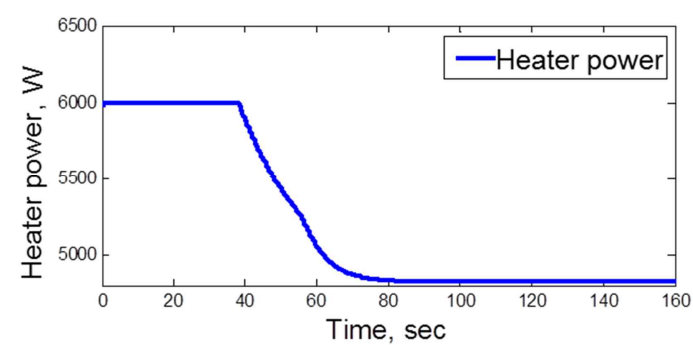

Figure13: Heater power

It is seen from Fig. 13 that the heater consumes $4.8 \mathrm{~kW}$ to $6 \mathrm{~kW}$ to satisfy the cabin temperature requirement.

Due to the power consumption of the heater, the EV range of the target vehicle is decreased from $57.6 \mathrm{~km}$ to $30.2 \mathrm{~km}$ (Fig. 14).

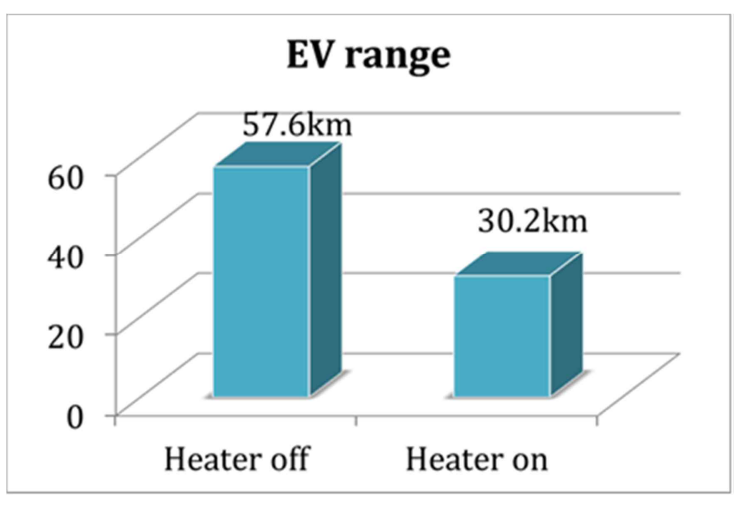

Figure14: Simulation results

\section{Conclusion}

Component design of various $\mathrm{x}-\mathrm{EV}$ s was performed using the virtual integrated development environment (VIDE).

Vehicle performance simulator of $\mathrm{x}$-EVs was developed using component library and controller model. The simulators were validated by experiment and commercial software. Using the VIDE, the EV range and acceleration performance of the $\mathrm{x}$-EVs were evaluated in design of the motor and battery specifications. An electric heater was selected as a design example and was applied to the target $\mathrm{x}-\mathrm{EV}$ to investigate the EV range using the VIDE. It is expected that the VIDE can be used in component design of the $\mathrm{x}-\mathrm{EV}$ s.

\section{Acknowledgments}

This work is financially supported by the Ministry of Knowledge Economy (MKE). 


\section{References}

[1] L. Situ, Electric Vehicle Development: The past, Present \& Future, 3rd International Conference on Power Electronics Systems and Applications, K210509135, 2009

[2] J. Liu and H. Peng, Control Optimization of a Power-Split Hybrid Vehicle, presented at Amer. Control Conf. Adv. Intell. Mechatron, Monterey, CA, 2005

[3] P. Srinivasan and Kothalikar U. M, Performance Fuel Economy and $\mathrm{CO} 2$ Prediction of a Vehicle using AVL Cruise Simulation Techniques, SAE, 2009-01-1862

[4] C. Ma, J. Kang, W. Choi, M. Song, J. Ji and H. Kim, Comparative Study on Power Characteristics and Control Strategies for Plug-in Hybrid Electric Vehicle, IJAT, Vol. 12, No. 3, pp. 505-516, 2012

[5] C. Ma, M. Song, S. Choi, K. Jeong and H. Kim, Development of Efficiency based Mode Control Algorithm for Plug-in Hybrid Electric Vehicle, IEEE Vehicle Power and Propulsion Conference, Seoul, Korea, 2012

[6] J. Park, C. Jeong, C. Ma, M. Suh, H. Kim and S. Hwang, Virtual Integrated Development for the Components Design of Eco-friendly Vehicle, EVS-26, 2012

[7] S. Abdul Rahman, N. Zhang and J. Zhu, Modeling and Simulation of an Energy Management System for Plug-in Hybrid Electric Vehicles, Australasian Universities Power Engineering Conference (AUPEC'08), 2008

[8] D. Karbowski, S. Pagerit, J. Kwon, A. Rousseau and K. Pechmann, Argonne National Laboratroy, Fair Comparison of Powertrain Configurations for Plug-In Hybrid Operation Using Global Optimization, SAE-2009-01-1334

[9] M. Miller, A. Holmes, B. Conlon and P. Savagian, General Motors Company, The GM 'Voltec' 4ET50 Multi-Mode Electric Transaxle, SAE-2011-01-0887

\section{Authors}

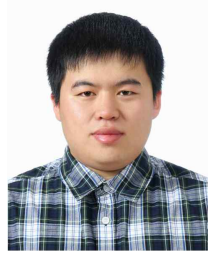

Chao Ma received a bachelor degree in mechanical engineering from Shandong University at Shandong, China, in 2008. And he received the master degree in mechanical engineering from Sungkyunkwan University, Korea, in 2010. Since 2010, he is studying as a Ph.D student at Sungkyunkwan University. His main research interests focuses on the powertrain system, control strategy of HEV, PHEV and EV. Recently, He is interested in design of the HEV and plug-in HEV, the evaluation of powertrain component performances.

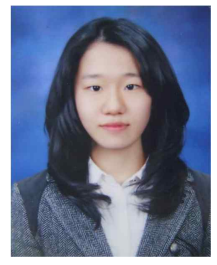

Heejin Shin received the B.S. degrees in mechanical engineering from Sungkyunkwan University, Korea, in 2013, where she is currently working toward the M.S. degree. Her research interests include the modeling and design for electric vehicles and plugin hybrid electric vehicles.

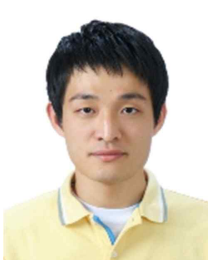

Seul Gi received a Bachelor degree in mechanical engineering from Sungkyunkwan University, Korea, 2013. He is studying as a Master Degree student at Sungkyunkwan University. His research interests include the powertrain system, control strategy of HEV, PHEV and EV.

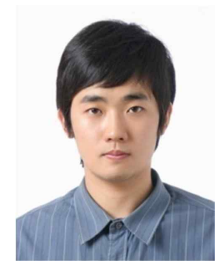

Minseok Song received B.S and M.S in mechanical engineering from Sungkyunkwan University, Korea, in 2009 and 2011, where he has been working toward $\mathrm{Ph}$. D. degree. His research interests include modeling and control of powertrain system for hybrid electric vehicle and plug-in hybrid electric vehicle.

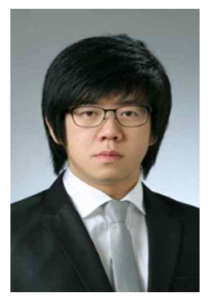

Jinhyun Park received the B.S. degrees in mechanical engineering from Sungkyunkwan University, Korea, in 2009 , where he is currently working toward the Ph.D. degree. His research interests include the modeling, design, and embedded systems for electric vehicles and hybrid electric vehicles.

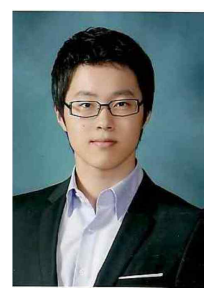

Choong-Min Jeong received his B.S. degree in Mechanical Engineering from Sungkyunkwan University, Korea, in 2010. Jeong is currently a doctoral student at Sungkyunkwan University. His research interests include structural analysis, optimization, and human factors

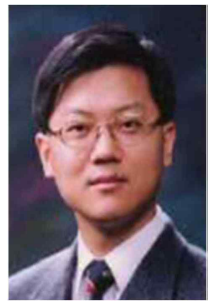

Sung-Ho Hwang received the B.S. degree in mechanical design and production engineering and the M.S. and Ph.D. degrees in mechanical engineering from Seoul National University, Seoul, Korea, in 1988, 1990, and 1997, respectively. He is currently an Associate Professor with 
the School of Mechanical Engineering, Sungkyunkwan University, Suwon, Korea. His research interests include automotive mechatronics systems for fuel cell and hybrid electric vehicles and embedded systems for $\mathrm{x}$-by-wire systems.

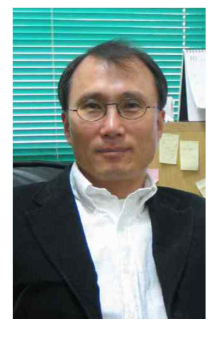

Myung-Won Suh received his B.S. degree in Mechanical Engineering from Seoul National University, Republic of Korea, in 1981. He then received his M.S. degree from the Korea Advanced Institute of Science and Technology in 1983 and his Ph.D. from the University of Michigan in 1989. Dr. Suh is currently a professor at the School of Mechanical Engineering in Sungkyunkwan University, Korea. Dr. Suh' $s$ research interests include structural analysis, optimization, human factors, and evaluation of reliability.

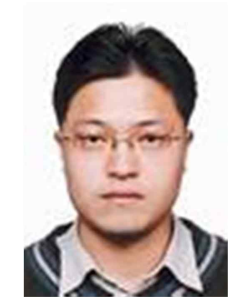

component.

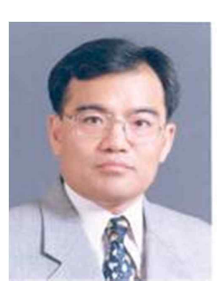

Kiyun Jeong is a senior researcher in Intelligent Control System Research Center of Korea Automotive Technology Institute. His main research interests include car experiments, component experiments and performance evaulation of vehicle and

Hyunsoo Kim received a Ph.D. degree in mechanical engineering from the University of Texas at Austin, Texas, USA, in 1986. Since 1986, he has worked as a Professor, Chairman, Dean of the College of Engineering at Sungkyunkwan University and Division President of the Korean Society of Automotive Engineers. His main research interests include Hybrid Electric Vehicle (HEV) transmission system design, regenerative braking, and optimal power-distribution algorithms for HEV and vehicle stability control for HEV and In-wheel Electric Vehicles. 